\title{
Polypharmacy, multiple natural health products and hepatotoxicity
}

\author{
Kosta Cvijovic MSc Pharm PhD, Heather Boon BScPhm PhD, Walter Jaeger MSc Pharm PhD, Sunita Vohra MD MSc;
} for the SONAR group

A 53-year-old woman with a history of asthma, depression and moderate-toheavy consumption of alcohol had presented to the emergency department with a threemonth history of increasing fatigue and jaundice. She had reported consuming three or four beers on a regular basis and a few glasses of wine three times weekly. Over the past three months, she had been taking six prescription medications (Table 1) $)^{1-3}$ and seven natural health products (Table 2). ${ }^{4-12}$ Her bilirubin level had been elevated (281 [normal 3.4-22] $\mu \mathrm{mol} / \mathrm{L}$ ), as had her liver enzyme levels (alanine transaminase 755 [normal 8-56] U/L and alkaline phosphatase 273 [normal 42-98] U/L). An ultrasound of her abdomen had been consistent with cirrhosis, and the presumptive diagnosis had been cirrhotic liver disease. She had been advised to stop using alcohol and all of the natural health products.

Despite taking this advice, the patient's jaundice and fatigue worsened. She presented to the emergency department 12 days later, at which time she was admitted to hospital. Her physical exam showed asterixis, spider nevi and ascites, and she seemed mildly confused. A test showed that she was immune to hepatitis B. A blood test for hepatitis $\mathrm{C}$ was negative. Her levels of ceruloplasmin, $\alpha-1$ antitrypsin, antimitochondrial antibodies, antinuclear antibody, and antismoothmuscle antibody were normal. Her immunoglobulin levels were elevated (immunoglobulin G 20.4 [normal 6.9416.18 ] g/L, immunoglobulin A 6.11 [normal 0.704.00] $\mathrm{g} / \mathrm{L}$ and immunoglobulin $\mathrm{M} 3.15$ [normal $0.60-3.00] \mathrm{g} / \mathrm{L})$. Her liver function tests remained abnormal (bilirubin $441 \mu \mathrm{mol} / \mathrm{L}$, alanine transaminase $317 \mathrm{U} / \mathrm{L}$ and alkaline phosphatase $247 \mathrm{U} / \mathrm{L}$ ), and a repeat ultrasound of her abdomen was still consistent with cirrhosis. There was no evidence of thrombosis in the hepatic or portal veins and no biliary dilatation. A transjugular biopsy of the liver showed submassive necrosis without the features of alcoholic hepatitis (Figure 1).
The differential diagnosis was submassive hepatic necrosis causing hepatic encephalopathy, due to either autoimmune hepatitis or drug toxicity. Liver injury as a result of alcohol use was considered unlikely because of the patient's very high level of alanine transaminase and the results of the biopsy of her liver. A timeline showing the patient's use of prescription and nonprescription medications is shown in Figure 2.

The patient's condition eventually improved with treatment that included diuretics, lactulose and prednisone, followed by azathioprine.

The case of this patient was evaluated through the multicentre Pharmacy Study of Natural Health Product Adverse Reactions (SONAR). ${ }^{13}$ We concluded that the entire combination of drugs, natural products and alcohol taken by our patient was possibly related to her hepatic symptoms. A single causative agent could not be isolated.

\section{Discussion}

It is important to determine potential adverse events that may be caused by medications, natural health products or illicit drugs, or combinations. Both passive and active surveillance can provide information on adverse reactions.

Passive surveillance usually requires health care professionals and patients to voluntarily report adverse events. Passive surveillance accounts for most of the postmarketing reporting of adverse events in Canada. The major drawbacks of passive surveillance are that meaningful estimates of inci-

\section{- KeY POINTS}

- Natural health products such as herbs, vitamins and amino acids may interact with prescription drugs with potentially serious consequences, but establishing solid empirical links is challenging.

- Clinicians should routinely ask patients whether they are taking any complementary or alternative medications.
Competing interests: Dr. Sunita Vohra holds grant funding from the Canadian Institutes of Health Research, Health Canada and the Canadian Patient Safety Institute; she receives salary support as an Alberta Innovates - Health Solutions Health Scholar. No other competing interests were declared.

This article has been peer reviewed.

Correspondence to: Dr. Sunita Vohra, care@med.ualberta.ca

CMAJ 2011.DOI:10.1503 /cmaj.091948 
dence cannot be generated, the quality of reports tends to be low and it is well-known for underreporting. ${ }^{14}$ In contrast, active surveillance involves protocol-driven screening of risk groups, which in turn allows for more accurate estimates of incidence and the generation of reports that are more consistent and of a higher quality. ${ }^{4}$

This case demonstrates an example of active surveillance. This type of process can be used to assess potential adverse events caused by medications or natural health products. It also illustrates the considerable uncertainties in using case reports to determine potential adverse effects.

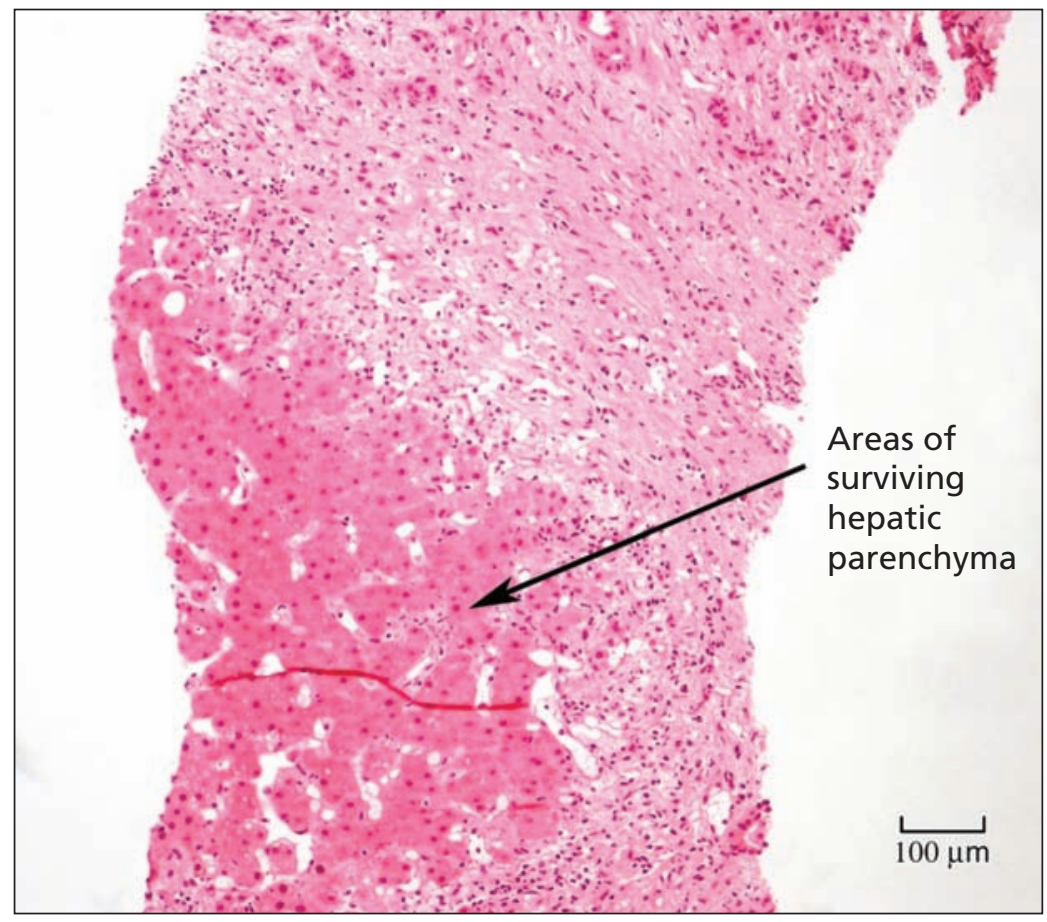

Figure 1: Biopsy from the central liver of a 53-year-old woman who presented with jaundice and fatigue. Areas of surviving hepatic parenchyma (arrow) and marked loss of hepatocytes can be seen. Hematoxylin and eosin stain, original magnification $\times 100$.

\section{Step 1: Collection of information and review of adverse event databases}

We completed a comprehensive review of the pubished literature (using the Medline and EMBASE search engines) on all prescription medications and natural health products used by the patient. Several of the natural health products have been associated with hepatotoxicity; however, much of the information about these associations is from studies done on animals or in vitro, and precise dosage information is limited..$^{4-12,15}$ Both venlafaxine and varenicline have been reported to cause hepatotoxicity in patients, especially in those with underlying liver conditions. ${ }^{1-3}$ Tables 1 and 2 provide summaries of the patient's medications and any published evidence of hepatotoxicity associated with their use.

\section{Step 2: Analysis of medications}

The harms associated with natural health products may be due to ingredients that are not listed on their labels (i.e., contaminants). Samples of all of the natural health products taken by our patient, with the exception of the human growth hormone product (GHR), which was no longer available in Canada, were tested for the possible presence of contaminants. Multiple samples of conjugated linoleic acid, methylsulfonylmethane, NutriMinC and Softcap Fish Oil were analyzed by gas chromatography/mass spectrometry and manually screened for steroids using ultraviolet light. None of the samples were found to contain adulterants or contaminants.

\section{Step 3: Classifying probable adverse effects}

Commonly used criteria for evaluating probable relationships between adverse events and the use of any product (or interactions between products)

\begin{tabular}{|c|c|c|}
\hline Product & Intake frequency & Potential hepatotoxicity \\
\hline $\begin{array}{l}\text { Budesonide/formoterol fumarate } \\
\text { dihydrate }\end{array}$ & $200 \mu \mathrm{g}$ and $6 \mu \mathrm{g}$, twice daily & None reported \\
\hline Estradiol transdermal patch & $\begin{array}{l}50 \mu \mathrm{g} / \mathrm{d}, \text { patch changed every } \\
2 \text { weeks }\end{array}$ & None reported \\
\hline Lorazepam & $1 \mathrm{mg}$, once daily & None reported \\
\hline Progesterone & 100 mg, unknown frequency & None reported \\
\hline Varenicline & $0.5 \mathrm{mg}$, once daily & $\begin{array}{l}\text { Case report of hepatic injury at } 0.5 \mathrm{mg} / \mathrm{d} \text { to } 1 \mathrm{mg} \text { twice daily } \\
\text { when underlying alcoholic liver disease is present; }{ }^{1} \text { three } \\
\text { case reports of hepatotoxicity when used concomitantly } \\
\text { with other medications in the Canada Vigilance Database }\end{array}$ \\
\hline Venlafaxine & $150 \mathrm{mg}$, unknown frequency & $\begin{array}{l}\text { Case report of liver toxicity at } 37.5 \mathrm{mg} / \mathrm{d} \text { in patient with } \\
\text { history of liver disease; }^{2} \text { additional reports at higher doses }\end{array}$ \\
\hline
\end{tabular}


are summarized in Box 1. ${ }^{16,17}$ Adverse events that cannot be classified as probable can fall into one of the following three categories: possible; doubtful or unlikely; or unassessable or unclassifiable. A designation of unassessable or unclassifiable is usually due to a lack of information. Based on our review, we could not isolate a single causative agent. It is possible that it was the combination of medications, natural products and alcohol taken by our patient that led to her symptoms.

\section{Identifying possible adverse reactions}

There are resources available to help physicians determine if a medication or natural health prod- uct is potentially causing an adverse reaction for a patient. Canada's national passive surveillance system is MedEffect. Health Canada maintains a searchable Adverse Reaction Database accessible from the MedEffect homepage and regularly issues advisories, warnings and recalls using the information collected from voluntary reports of suspected adverse reactions (www.hc-sc.gc.ca /dhp-mps/medeff/index-eng.php). In the US, the Food and Drug Administration's MedWatch provides a similar function (www.fda.gov/safety /MedWatch). (Additional resources for information on adverse events and natural health products are summarized in Box 2.)

Table 2: Potential hepatotoxocity of natural health products used by a 53-year-old woman who presented with jaundice and fatigue

\begin{tabular}{|c|c|c|c|}
\hline Product & Ingredients & Frequency of intake & Potential hepatotoxicity \\
\hline Acidophilus with bifidus & $\begin{array}{l}\text { Lactobacillus rhamnosus } 50 \% \\
\text { ( } 3 \text { billion CFU), Lactobacillus casei } \\
30 \% \text { ( } 1.8 \text { billion CFU), Lactobacillus } \\
\text { acidophilus } 10 \% \text { ( } 6 \text { million CFU), } \\
\text { Bifidobacterium longum } 10 \% \text { ( } 6 \\
\text { million CFU) }\end{array}$ & Three times daily orally & None reported in the literature \\
\hline Conjugated linoleic acid & $\begin{array}{l}\text { Tonalin } 1000 \mathrm{mg}, \mathrm{CLA} 74 \%-82 \% \text {, } \\
\text { PA } 6 \% \text {, OA } 10 \%-20 \% \text {, SA } 3 \%\end{array}$ & Three times daily orally & $\begin{array}{l}\text { Report of CLA toxicity, no dose } \\
\text { provided; }{ }^{4} \text { PA shows toxicity in } \\
\text { vitro }^{5}\end{array}$ \\
\hline $\begin{array}{l}\text { GHR human growth } \\
\text { hormone* }\end{array}$ & $\begin{array}{l}\text { Anterior pituitary } 20 \mathrm{mg} \text { (porcine } \\
\text { source), hypothalamus } 5 \text { mg, amino } \\
\text { acid complex (histidine, } \\
\text { methionine, arginine, aspartic acid, } \\
\text { glutamic acid, glycine, isoleucine, } \\
\text { leucine, lysine, phenylalanine, } \\
\text { proline, serine, threonine, tyrosine, } \\
\text { valine) } 300 \mathrm{mg} \text {, Panax ginseng } \\
20 \mathrm{mg} \text {, phylosterol complex } \\
\text { ( } \beta \text { sitosterol, campesterol, } \\
\text { phosphatidylcholine, } \\
\text { phospathidylethanolamine, } \\
\text { phosphatidylinositol, phytosterol, } \\
\text { stigmasterol) } 10 \text { mg, soy } \\
\text { phosphatide serene } 40 \%\end{array}$ & Unknown frequency & $\begin{array}{l}\text { - Histidine shows toxicity in } \\
\text { vitro, }{ }^{6-8} \text { no adverse effects in } \\
\text { humans at }<4.5 \mathrm{~g} / \mathrm{d}^{7} \\
\text { - Evidence for methionine } \\
\text { toxicity in animals and } \\
\text { humans } \\
\text { - No adverse effects at }<5 \mathrm{~g} / \mathrm{d} \\
\text { - Liver dysfunction resulted } \\
\text { with } 30 \mathrm{~g} \text { intravenously } \\
\text { - Clinical report of protracted } \\
\text { cholestatic hepatitis after use } \\
\text { of product containing ginseng } \\
\text { (Protstata), dose not reported }\end{array}$ \\
\hline Methylsulfonylmethane & Methylsulfonylmethane $1000 \mathrm{mg}$ & Once to three times daily & None reported in the literature \\
\hline NutriMinC & $\begin{array}{l}\text { Vitamin A (retinyl palmitate) } \\
188 \mu \mathrm{g} \text {, vitamin C (calcium sorbate) } \\
15 \mathrm{mg} \text {; ubidecarenone } 3.75 \mathrm{mg} ; \\
\alpha \text { lipoic acid } 3.75 \mathrm{mg} \text {, flax seed oil } \\
520 \mathrm{mg} \text { ( } 70 \% \alpha \text { linolenic acid), } \\
\text { vitamin } \mathrm{E}(d-\alpha \text {-tocopheryl acetate) } \\
7.5 \mathrm{mg}\end{array}$ & Two capsules twice daily orally & $\begin{array}{l}\text { - Clinical evidence of } \\
\text { hepatotoxicity when vitamin } \\
\text { A dose }>2.5-3 \text { times } \\
\text { recommended dose for }> \\
10 \mathrm{yr} \text { or }>70-80 \text { times } \\
\text { recommended dose for } 1 \mathrm{yr} \\
\text { - Lowest dose associated with } \\
\text { cirrhosis is } 25000 \text { IU for } 6 \mathrm{yr}^{10} \\
\text { - Radical ascorbate from } \\
\text { vitamin C may be harmful } \\
\text { - Evidence of ubidecarenone } \\
\text { toxicity in animals }\end{array}$ \\
\hline Softcap Fish Oil & $\begin{array}{l}\text { Fish body oil } 1000 \mathrm{mg} \text {, EPA } 180 \mathrm{mg} \text {, } \\
\text { DHA } 120 \mathrm{mg}\end{array}$ & Twice daily orally & $\begin{array}{l}\text { Evidence of fish oil toxicity in } \\
\text { animals }^{12}\end{array}$ \\
\hline Vitamin D & Vitamin D (cholecalciferol) 1000 IU & Once daily orally & None reported in the literature \\
\hline
\end{tabular}


As with other passive surveillance systems, MedEffect is subject to incomplete, inaccurate reporting and underreporting. For most reports of adverse effects, inferences regarding causality are not possible.

People often consider natural health products to be safe despite reported pharmacodynamic and pharmacokinetic interactions with conventional pharmaceuticals. ${ }^{18}$ This perception of safety may mean there are fewer reports of suspected adverse events related to natural health products than reports of adverse events related to conventional medications. ${ }^{17,19}$

Because many Canadians use natural health products (and one third of Canadians report using more than three products concurrently), ${ }^{20}$ it is prudent for physicians to ask about their use in the routine medical history and to consider potential

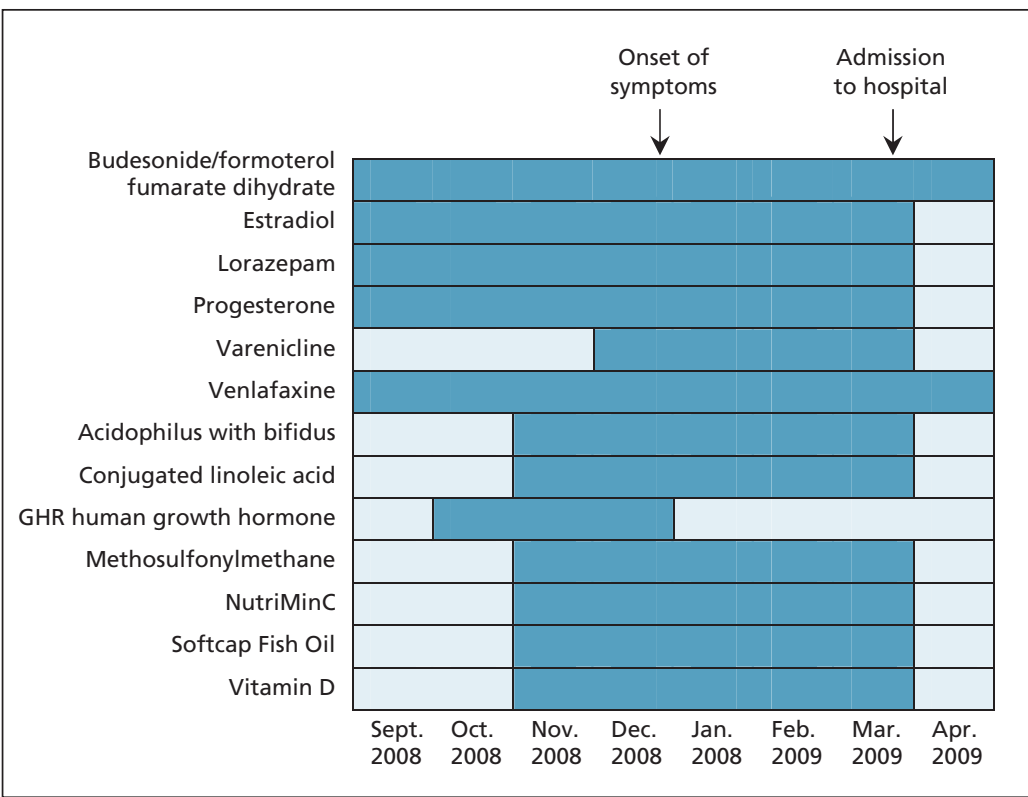

Figure 2: Timeline showing our patient's exposure (shaded) to natural health products and prescription medications. The start of the patient's adverse reaction and the point at which the patient was admitted to hospital are indicated.

\section{Box 1: Criteria for evaluating adverse events}

- The Naranjo scale: ${ }^{16} \mathrm{~A}$ probable adverse reaction is indicated when there are previous reports of adverse reactions, when the onset of reaction is consistent with the time course of administration of the drug and when there is a positive response to withdrawal of the drug (dechallenge).

- The Horn Drug Interaction Probability Scale (DIPS): ${ }^{17}$ A probable interaction is indicated when there are previous reports of interactions, when the reaction diminishes in a manner consistent with the time course of withdrawal of the drug, when there is a positive response to withdrawal of the drug (dechallenge) and when the interaction is consistent with the known pharmacology of the drug.

- World Health Organization (WHO) criteria: ${ }^{16} \mathrm{~A}$ probable or likely adverse reaction is indicated if the clinical event occurs in a reasonable time frame after administration of the drug, if the event is unlikely to be due to concurrent disease and if the response to withdrawal of the drug (dechallenge) is clinically plausible. interactions in a differential diagnosis when there is an unexpected response to treatment. Many natural health products may indeed be safe, and new Canadian regulations governing their labelling could help consumers be more wellinformed when choosing treatments. Still, when these products are combined with multiple prescription and nonprescription medications, serious problems can occur and caution is warranted. Physicians can help improve knowledge about these products by reporting suspected adverse reactions to the Canada Vigilance Program via MedEffect.

Natural health products are not regulated in the same way as prescription drugs, and information on which natural health product/drug combinations are safe and which are potentially associated with adverse events remains largely unknown.

Box 2: Resources for information on adverse events and natural health products

- Barnes J, Anderson LA, Phillipson JD. Herbal medicines. 3rd ed. London (UK): Pharmaceutical Press; 2007

- Boon H, Smith M. 55 most common medicinal herbs. 2nd ed. Toronto (ON): Robert Rose; 2009

- Canada Vigilance Program (via MedEffect) www.hc-sc.gc.ca/dhp-mps/medeff/indexeng.php.

- European Medicines Agency www.ema.europa.eu

- Evidence-based reviews of natural health products www.CAMline.ca

- General Information about natural health products

www.hc-sc.gc.ca/dhp-mps /prodnatur/index-eng.php

- National Centre for Complementary and Alternative Medicine http://nccam.nih.gov

- Natural Health Products Directorate of Health Canada

www.hc-sc.gc.ca/ahc-asc/branch-dirgen/hpfbdgpsa/nhpd-dpsn/index-eng.php

- Natural health product/drug interaction tool www.cpjournal.ca/doi/full/10.3821/1913701X-142.5.224

- Natural Medicines Comprehensive Database (subscription required) www.naturaldatabase.com

- Natural Standard, The Authority on Integrative Medicine (subscription required) www.naturalstandard.com

- Pediatric evidence on complementary and alternative medicine

www.pedcam.ca 
Coordinated national surveillance initiatives will hopefully advance clinical knowledge in this poorly understood area.

\section{References}

1. Franck AJ, Sliter LR. Acute hepatic injury associated with varenicline in a patient with underlying liver disease. Ann Pharmacother 2009; 43:1539-43.

2. Sencan I, Sahin I, Ozcetin A. Low-dose venlafaxine-associated liver toxicity in chronic hepatitis [letter]. Ann Pharmacother 2004;38:352-3.

3. Horsmans Y, De Clereq M, Sempeux C. Venlafaxine-associated hepatitis [letter]. Ann Intern Med 1999;130:944.

4. Ramos R, Mascarenhas J, Duarte P, et al. Conjugated linoleic acid-induced toxic hepatitis: first case report. Dig Dis Sci 2009 54:1141-3.

5. Leekumjorn S, Wu Y, Sum AK, et al. Experimental and computational studies investigating trehalose protection of HepG2 cells from palmitate-induced toxicity. Biophys $J$ 2008;94:2869-83.

6. Rauen U, Klempt S, De Groot H. Histidine-induced injury to cultured liver cells, effects of histidine derivatives and of iron chelators. Cell Mol Life Sci 2007;64:192-205.

7. Scarna A, Gijsman HJ, McTavish SF, et al. Effects of a branchedchain amino acid drink in mania. Br J Psychiatry 2003;182:210-3.

8. Garlick PJ. The nature of human hazards associated with excessive intake of amino acids. J Nutr 2004;134:1633S-9S.

9. Hamid S, Rojter S, Vierling J. Protracted cholestatic hepatitis after the use of prostata. Ann Intern Med 1997;127:169-70.

10. Leo MA, Lieber CS. Alcohol, vitamin A, and beta-carotene: Adverse interactions, including hepatotoxicity and carcinogenicity. Am J Clin Nutr 1999;69:1071-85.

11. Kitano M, Watanabe D, Oda S, et al. Subchronic oral toxicity of ubiquinol in rats and dogs. Int J Toxicol 2008;27:189-215.

12. Ritskes-Hoitinga J, Verschuren PM, Meijer GW, et al. The association of increasing dietary concentrations of fish oil with hepatotoxic effects and a higher degree of aorta atherosclerosis in the ad lib.-fed rabbit. Food Chem Toxicol 1998;36:663-72.

13. Cvijovic K, Boon H, Brulotte J, et al. Pharmacy study of natura health product adverse reactions (SONAR): piloting an active surveillance model in community pharmacies. [abstract]. Pharmaceut Biol 2009; 47(Suppl 1):21.

14. Alvarez-Requejo A, Carvajal A, Begaud B, et al. Underreporting of adverse drug reactions. Estimate based on a spontaneous reporting scheme and a sentinel system. Eur J Clin Pharmacol 1998;54:483-8.
15. Fallon MB, Boyer JL. Hepatic toxicity of vitamin A and synthetic retinoids. J Gastroenterol Hepatol 1990;5:334-42.

16. The Global Intelligence Network for Benefits and Risks in Medicinal Products. Causality assessment of suspected adverse reactions. Uppsala (Sweden): Uppsala Drug Monitoring Centre WHO Collaborating Centre for International Drug Monitoring.

17. Horn JR, Hansten PD, Chan LN. Proposal for a new tool to evaluate drug interaction cases. Ann Pharmacother 2007;41: 674-80.

18. Smith JW, Seidl LG, Cluff LE. Studies on the epidemiology of adverse drug reactions. V. Clinical factors influencing susceptibility. Ann Intern Med 1966;65:629-40.

19. Naranjo CA, Busto U, Sellers EM, et al. A method for estimating the probability of adverse drug reactions. Clin Pharmacol Ther 1981;30:239-45.

20. Bailey DG, Dresser GK. Natural products and adverse drug interactions. CMAJ 2004;170:1531-2.

Affiliations: From the Leslie Dan Faculty of Pharmacy (Cvijovic, Boon), University of Toronto, Toronto, Ont.; the Department of Clinical Pharmacy and Diagnostics (Cvijovic, Jaeger), University of Vienna, Vienna, Austria; CARE Program, Department of Pediatrics, Faculty of Medicine and School of Public Health (Vohra), University of Alberta, Edmonton, Alta.

Contributors: Kosta Cvijovic wrote the paper and collected the data on which the paper is based. All of the authors contributed substantially to the article's conception and design, played an important role in the interpretation and analysis of the data, revised the article and made significant contributions to it and approved the final version submitted for publication. Additional members of the SONAR group are listed in Appendix 1 (available at www.cmaj.ca /lookup/suppl/doi:10.1503/cmaj.091948/-/DC1).

Acknowledgements: All of the assays used were developed at the University of Alberta Hospital (Edmonton, Alta.). The SONAR team thanks the University of Alberta Department of Laboratory Medicine and Pathology, Division of Anatomic Pathology, for providing the biopsy image. The authors also thank Dr. Vincent Bain of the Division of Gastroenterology, Department of Medicine, University of Alberta, for his continuous and detailed input and review of this paper. 